\title{
Effects of Fungal Strains on Seeds Germination of Millet and Striga Hermonthica
}

\author{
Mohammed M. Hassan ${ }^{1, *}$, Hussien M. Daffalla ${ }^{2}$, Hanan Ibrahim Modwi ${ }^{1}$, Magdoleen G. Osman ${ }^{2}$, \\ Inas Ishag Ahmed ${ }^{1}$, Migdam E. Abdel Gani ${ }^{1}$, Abdel El Gabar E. Babiker ${ }^{3}$ \\ ${ }^{1}$ Environment and Natural Resources Research Institute, Khartoum, Sudan \\ ${ }^{2}$ Commission for Biotechnology and Genetic Engineering, Khartoum, Sudan \\ ${ }^{3}$ Sudan University of Science and Technology, College of Agricultural Studies, Khartoum, Sudan \\ *Corresponding Author: mohkadis@yahoo.com
}

Copyright (C) 2014 Horizon Research Publishing All rights reserved.

\begin{abstract}
The effects of aqueous extracts of three fungi were evaluated on three millet varieties and Striga hermonthica seed germination. Striga seeds were inoculated with Trichoderma viride, T. harzianum and Pencillium spp. in presence of GR24. T. viride at concentration $25 \%$ improved significantly Striga germination (90.3\%) compared to control (85.4\%) in presence of $0.1 \mathrm{ppm}$ GR24. However the same fungi $T$. viride at $75 \%+0.01 \mathrm{ppm}$ GR24 was significantly inhibited Striga seed germination $(0 \%)$. Seeds of three millet verities were treated with $0-75 \%$ concentrations of $T$. viride or Pencillium spp. The results showed that variety MCSRC recorded $100 \%$ final germination (FG) in all treatments. However, Mallit and El-Fasher varieties showed $100 \%$ FG when treated with the concentrations $0 \%$ (control), $25 \%$ or $50 \%$ only and decreased with application of $75 \%$ inoculums. The maximum viguor index (805) occurred on El-Fasher with $50 \% T$. viride compared to its control (787). The minimum viguor index (335) was recorded by Mallit in $75 \%$ Pencillium compared to its control (752). When comparing the three varieties in germination rate, MCSRC showed increase in germination rate with increasing inoculums concentration, while Mallit and El-Fasher showed decrease with increasing inoculums concentration. Mallit recorded the highest shoot length $(8.18 \mathrm{~cm})$ with $75 \% T$. viride. On the other hand, El-Fasher recorded the highest root length (15.23 $\mathrm{cm})$, shoot dry weight $(8.35 \mathrm{~g})$ and root dry weight $(4.7 \mathrm{~g})$ compared with control. Generally, MCSRC appear to be more tolerant to fungal application in the highest concentration followed by El-Fasher and Mallit although no significant differences were observed among millet varieties.
\end{abstract}

Keywords Germination, Millet, Striga, Trichoderma, Pencillium.

\section{Introduction}

Biological control is considered an attractive approach for suppressing parasitic weeds. Some species of fungi can secrete substances or metabolites that have very specialized activity, being lethal to a particular group of life forms. Since 1963, fungi have received great attention as biocontrol organisms against pests (1). Extensive work has been carried out in order to identify fungi with toxic metabolites potential capabilities as natural herbicides. Thus many screenings for activities of fungi can be found in the literature and some promising agents have been found $(2 ; 3)$. These antagonistic effects could be an alternative strategy to look for natural products that will inhibit the germination of Striga seeds. Bioherbicides can be integrated into intensively managed agriculture production systems because of their potential to yield quick and reliable levels of weed control. The use of phytopathogenic fungi and/or their toxic metabolites to control weeds is interesting since their biocontrol agents are highly specific (4) and their toxic metabolites are possibly natural herbicides (2). Although bioherbicides can be used as the sole option for the management of certain weeds in particular situations, typically they have been used as a minor supplement to conventional chemical herbicides (5). A large number of phytopathogenic fungi have been, or are being, evaluated for their effectiveness against parasitic weeds. Despite the large number of micro-organisms surveyed, only some are considered effective candidates to control Striga hermonthica, but so far none of them has been used in large-scale application in the field. Clearly, finding a weed pathogen is only a preliminary step in a long process leading to the development of an effective and safe bioherbicide (6). Trichoderma species are free-living fungi that are growing vigorously in soil and plant root ecosystems (3). They have been widely studied for their capacity to stimulate plant growth or enhance defense mechanisms (7). Regarding plant growth, many Trichoderma spp were confirmed to increase germination rate and percentage of emergence, plant height, leaf area and dry weight (8). Most Trichoderma strains produce toxic metabolites that act as antibiotics or antifungal and compete with wide a range of 
pathogenic microorganisms to protect plants from disease ( 9 ; 10). It was estimated that $90 \%$ of fungi utilized for biocontrol were Trichoderma strains (1).

In view of the importance of sorghum and millet crops as major food crops for the Sudanese farmers and also for the reduction of the cultivated area due to Striga invasion, a screening experimentwere set up to investigate the inhibitory effect of three promising fungal isolates on Striga seed germination under laboratory condition and their effects on millet seeds germination and seedlings growth.

\section{Materials and Methods}

This experiment was conducted at the Environment and Natural Resources Research Institute, National Center for Research, Khartoum, Sudan laboratory during February April 2012.

\subsection{Inoculum Production of Fungal Strains}

Three candidate fungal isolates including Trichoderma viride, T. harzianum and Pencillium spp, were selected to evaluate their potential as mycoherbicides to control Striga. These fungal isolates were maintained on Potato Dextrose Agar media (PDA), amended with $0.05 \mathrm{~g} / \mathrm{L}$ chloramphenicol (Johnston and Booth 1983) and stored in the refrigerator at $4^{0} \mathrm{C}$. Starter cultures were made when required. The strains were mass cultured aseptically in $90 \mathrm{~mm}$ diameter Petri plates each containing $15 \mathrm{ml}$ of a freshly autoclaved PDA media. The plates were incubated in the dark at $28^{\circ} \mathrm{C}$ for 10 days. On the tenth day spore suspensions from the fungal inoculum were prepared by flooding the surface of the agar slant with $10 \mathrm{ml}$ sterile distilled water and the culture surface gently scraped to dislodge the spores. The spore suspension derived from two Petri plates from each fungal strains, were transferred separately to $500 \mathrm{ml}$ flask containing $400 \mathrm{ml}$ sterile distilled water. Flasks were shaken for 2 minutes to ensure that the spores were properly mixed. Three concentrations of each fungal strain (spore) were prepared $(75,50 \%$ and $25 \%)$. The fungal spore count for each fungal strains were determined with a haemocytometer, so that the final counts were determined as: $0.25 \times 10^{7}$ spore $/ \mathrm{ml}$, $0.12 \times 10^{5}$ spore $/ \mathrm{ml}$ and $0.06 \times 10^{3} \mathrm{spore} / \mathrm{ml}$ for $T$. viride, $0.72 \times 10^{7}, 0.36 \times 10^{5}$ and $0.18 \times 10^{3}$ spore $/ \mathrm{ml}$ for Pencillium spp., and $1.58 \times 10^{8}, 0.79 \times 10^{6}$ and $0.41 \times 10^{4}$ spore $/ \mathrm{ml}$ for $T$. harzianum.

\subsection{Effects of Fungal Strains on Striga Hermonthica Germination}

Striga hermonthica seeds were collected from Sinnar State, Sudan in 2009. The seeds were sterilized by immersion for $5 \mathrm{~min}$ in a $1 \%$ sodium hypochlorite solution. After rinsing with sterile distilled water, the seeds were plotted dry on Whatman No. 1 filter paper under a laminar flow hood.
Striga seeds were conditioned in water. Glass fiber filter papers $(\mathrm{GF} / \mathrm{C})$ discs $(8 \mathrm{~mm}$ diameter) were cut, wetted thoroughly with water and placed in an oven at $100{ }^{\circ} \mathrm{C}$ for $1 \mathrm{~h}$ to be sterilized and ready for further use. The sterilized discs, placed in $9 \mathrm{~cm}$ petri dishes lined with glass fiber filter papers $(\mathrm{GF} / \mathrm{C})$, were moistened with $5 \mathrm{ml}$ distilled water or inoculated with the respective fungal strains (as described above). About 25-50 surface disinfected S. hermothica seeds were sprinkled on each of the glass fiber discs in each Petri dish. The dishes, sealed with Para film, placed in black polythene bags were incubated at $30{ }^{\circ} \mathrm{C}$ in the dark for 10 days. For germination, glass filter paper discs containing Striga seeds, were plotted dry on filter paper (Whatman No. 1) to remove excess water and then transferred to sterile Petri dishes. Each disc was treated with $20 \mu \mathrm{l}$ aliquot of the germination stimulant (GR24). The experiment was set in a Completely Randomized Design with four replicates. The seeds were re-incubated in the dark at $30{ }^{\circ} \mathrm{C}$, and then examined for germination $24 \mathrm{~h}$ later using a stereomicroscope.

\subsection{Effect of Fungal Strains and their Concentrations on Millet Seed Germination}

\subsubsection{Collection and Preparation of Millet Seeds}

Two commercial millet varieties commonly grown in Sudan were used; Dami Mallit obtained from the north of Northern Darfur State and Dami El-Fasher from the centre of Northern Darfur State, in addition to an induced variety MCSRC which was provided by the Agricultural Research Corporation (ARC). The seeds were surface-sterilized by rinsing in $1 \%$ sodium hypochlorite (commercial $\mathrm{NaOCl}$ ) solution with gentle shaking for $3 \mathrm{~min}$ and then washed three times with sterilized distilled water to remove any remaining detergent (floating seeds were excluded).

\subsubsection{Pathogenicity Assay}

Ten sterilized seeds from each millet variety were selected and placed in 9-cm plastic Petri dish line with 4 layers of tissue papers. In this experiment only two fungal strains $T$. viridi and Pencillium spp. were used. Seeds were treated with three concentrations of the each fungal suspensions $(100,75$ and $50 \%)$. Five $\mathrm{ml}$ aliquot, of each concentration of all fungal strain were applied to the Petri-dishes. In the control treatment sterile distilled water was used. The Petri dishes were then sealed with aluminum foil and incubated at room temperature $\left(25 \pm 5^{\circ} \mathrm{C}\right)$ for 7 days. A seed was considered germinated when the tip of the radicle emerged 1 $\mathrm{mm}$ out of the seed coat. The plates were regularly checked for moisture. The number of germinated seeds was recorded daily and by the end of seven days the final percentage of germination ( $\mathrm{FG} \%$ ) was calculated. Germination rate (sum of germinations per day) was calculated using the formula described by Maguire (12):

$$
\mathrm{M}=\mathrm{n} 1 / \mathrm{t} 1+\mathrm{n} 2 / \mathrm{t} 2+\ldots .+\mathrm{nx} / \mathrm{tx},
$$

where $n 1, n 2, \ldots . n x$ are the numbers of the germinated seeds 
at times $t 1, t 2, \ldots . t x$ in days.

At the $7^{\text {th }}$ day of germination, ten normal seedlings were taken out carefully at random from each treatment, and measured from the tip of shoot to the tip of primary root. The lengths of shoots and roots $(\mathrm{cm})$ as well as the dry matters weights $(\mathrm{g})$ were measured.

Seedling vigour index (V) was computed according to Randahawa et al. (13) as follows:

$$
\mathrm{V}=\mathrm{L} \times \mathrm{FG} \text {, }
$$

Where $L$ is the mean seedling length (total shoot and root length in $\mathrm{cm}$ ) and $\mathrm{FG}$ is final germination percentage (\%).

The data were statistically analyzed using analysis of variance (ANOVA) for individual parameters and means were separated by least significant differences (LSD) test using Microsoft Excel program.

\section{Results and Discussion}

\subsection{Effects of Fungal Strains on Striga Seeds Germination}

In this experiment, the effects of three fungal strains on Striga seeds germination in response to GR24 at 0.01, and $0.1 \mathrm{ppm}$, were studied. Seeds treated with distilled water displayed negligible germination (Data not shown). GR24 at $0.01-1 \mathrm{ppm}$ effectively induced germination of water conditioned seed in a dose dependent - manner. The germination percentage of Striga seeds differed depending on the treatments and their concentrations (Figure 1). Significantly highest percentage germination $(90.03 \%)$ was recorded in seeds treated with $25 \%$ Trichoderma viride in presence of GR24 at $0.1 \mathrm{ppm}$ as compared to the control GR24. The results indicated a certain role of $T$. viride in promoting seed germination of Striga. However, no germination $(0.0 \%)$ was recorded when seeds were treated with $T$. viride at $75 \%$ in response to GR24 at $0.01 \mathrm{ppm}$. Furthermore, Striga seeds inoculated with Pencillium spp. and $T$. harzianum reduced germination by in response to GR24 as compared to the control. In among all fungal strains, the highest inhibitory effect on Striga seed germination was observed in Pencillium at concentrations 50\% in response to GR24 at both concentrations.

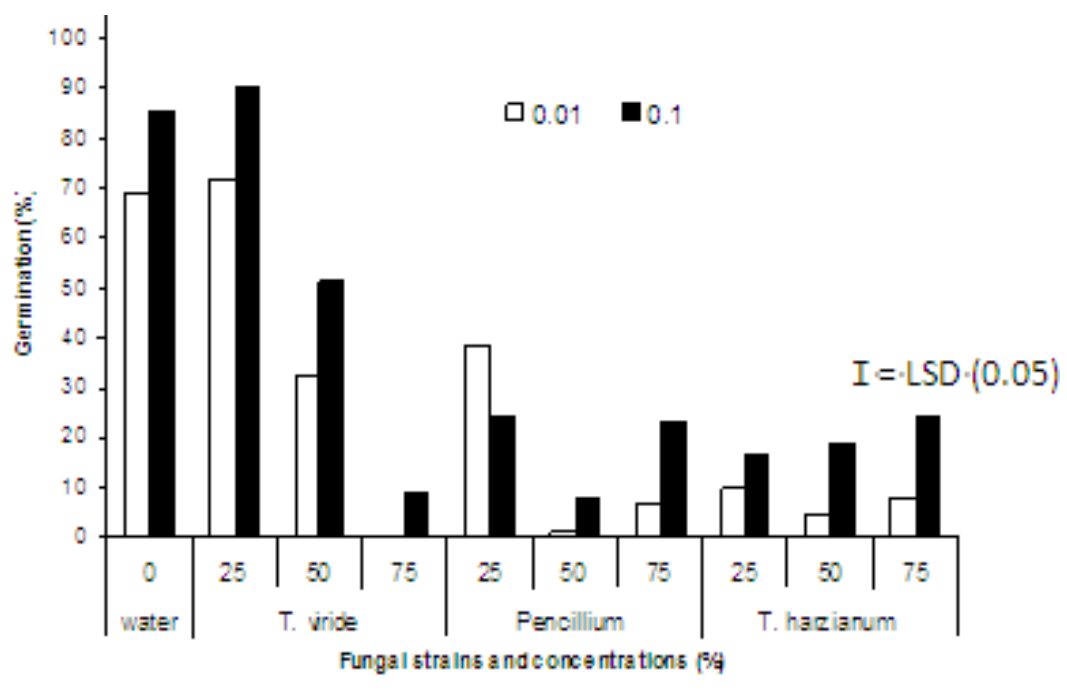

Figure 1. Effects of fungal strains on Striga hermonthica seed germination in response to GR24 $(0.01,0.1)$. Vertical bar (I) indicates LSD interaction $(P \leq$ $0.05)$.

Table 1. Effects of fungal strains on seed germination and seedling vigour of millet varieties after 7 days growth.

\begin{tabular}{|c|c|c|c|c|c|c|}
\hline \multirow[b]{2}{*}{ Millet variety } & \multicolumn{3}{|c|}{ Final Germination (\%) } & \multicolumn{3}{|c|}{ Vigour Index } \\
\hline & Mallit & El-Fasher & MCSRC & Mallit & El-Fasher & MCSRC \\
\hline Control & $100 \pm 0.0$ & $100 \pm 0.0$ & $100 \pm 0.0$ & $752 \pm 0.0$ & $787 \pm 0.0$ & $755 \pm 0.0$ \\
\hline \multicolumn{7}{|c|}{ T. viride $(\%)$} \\
\hline 25 & $100 \pm 0.0$ & $100 \pm 0.0$ & $100 \pm 0.0$ & $757 \pm 0.0$ & $788 \pm 0.0$ & $803 \pm 0.0$ \\
\hline 50 & $100 \pm 0.0$ & $100 \pm 0.0$ & $100 \pm 0.0$ & $758 \pm 0.0$ & $805 \pm 0.0$ & $680 \pm 0.0$ \\
\hline 75 & $78.6 \pm 2.3$ & $92.9 \pm 1.2$ & $100 \pm 0.0$ & $643 \pm 18.0$ & $611 \pm 8.0$ & $662 \pm 0.0$ \\
\hline \multicolumn{7}{|c|}{ Pencillium spp. (\%) } \\
\hline 25 & $100 \pm 0.0$ & $100 \pm 0.0$ & $100 \pm 0.0$ & $543 \pm 0.0$ & $693 \pm 0.0$ & $662 \pm 0.0$ \\
\hline 50 & $100 \pm 0.0$ & $100 \pm 0.0$ & $100 \pm 0.0$ & $523 \pm 0.0$ & $693 \pm 0.0$ & $632 \pm 0.0$ \\
\hline 75 & $64.3 \pm 3.5$ & $92.9 \pm 0.9$ & $92.9 \pm 0.2$ & $335 \pm 18.0$ & $588 \pm 5.4$ & $583 \pm 0.9$ \\
\hline
\end{tabular}

Values represent mean \pm standard error 


\subsection{Effects of Fungal Strains on Millet Seed Germination}

To ensure that fungus application on millet crop has no negative effect on millet growth and development, fungi with the same previous concentrations were also applied at axenic culture level on millet seeds. The data obtained on seed germination percentage, seedling vigour index and germination rate in different treatments are given in Table (1) and Fig (2).

The results revealed that there were no significant variations in response of millet seeds germination to various concentrations of fungal strains (Table 1). The lowest concentration of both fungal strains gave $100 \%$ germination as compared to the control. However, the highest concentration insignificantly decreased the germination percentages of millet varities(Table 1). MCSRC appears to be more tolerant to fungal application in the highest concentration followed by El-Fasher and Mallit.

The performance of seedlings of millet varieties vary (not significantly at $P \leq 0.05$ ) between the two strains (Table 1 ). The vigour index increased with $T$. viride fungal application up to the concentration $50 \%$ and then decreased with the concentration $75 \%$ less than the control. However, with Pencillium the vigour index decreased with increasing fungus concentration. The highest vigour index, albeit not significantly was obtained in $50 \% T$. viride (805) with El-Fasher.

Although fungal strains didn't severely affect the millet seed final germination percentage, they showed higher affects on germination rates. Figure (2) showed germination patterns of the millet varieties in response to the fungal strains. MCSRC millet showed increase in germination rate with increasing the concentration of the both fungus, while the seed of the two other varieties decreased in germination rate with increasing concentration of the inoculum.

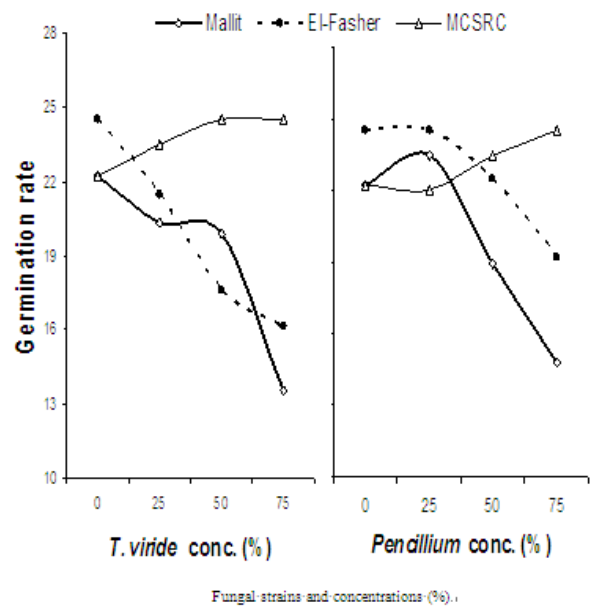

Figure 2. Effect of fungal strains at different concentrations on germination dynamic of millet varieties ( 7 days)

Trichoderma viride and $T$. harzianum include a great number of strains which are the most common used fungus for biocontrol purposes (1). Theses strains reported in many studies to enhance germination percentage as well as early germination of different plants $(14 ; 15)$. They reported to increase the germination rate of maize and beans (9), final germination of pearl millet (16), spinach, red beet, tomato and chicory (8), vigour index of chili (10) and pearl millet (16). Penicillium strains were reported to increase seed germination of many crops and inhibited other fungal pathogens (17). Among 20 fungal strains screened of their effects on seed germination and seedling vigour of rice, the authors found that the lowest inhibition of germination was recorded by Trichoderma and Penicillium strains. Islam and Borthakur (17) reported that both strains recorded the best germination percentage as Trichoderma $(93.57 \%)$ and Penicillium and (89.5\%) behind the control (95.3\%).

Table 2. Effects of fungal strains on seedling shoots and root length of millet varieties

\begin{tabular}{|c|c|c|c|c|c|c|}
\hline \multirow{2}{*}{ Millet variety } & \multicolumn{3}{|c|}{ Shoot length $(\mathrm{cm})$} & \multicolumn{3}{|c|}{ Root length $(\mathrm{cm})$} \\
\hline & Mallit & El-Fasher & MCSRC & Mallit & El-Fasher & MCSRC \\
\hline Control & $7.5 \pm 0.26$ & $7.8 \pm 0.81$ & $7.6 \pm 0.50$ & $14.7 \pm 3.02$ & $15.3 \pm 2.45$ & $13.4 \pm 1.96$ \\
\hline \multicolumn{7}{|c|}{ T. viride $(\%)$} \\
\hline 25 & $7.6 \pm 0.86$ & $7.9 \pm 0.50$ & $8.0 \pm 0.98$ & $8.2 \pm 2.10$ & $7.2 \pm 0.49$ & $12.2 \pm 0.37$ \\
\hline 50 & $7.6 \pm 0.50$ & $8.1 \pm 0.80$ & $6.8 \pm 1.08$ & $8.0 \pm 0.79$ & $6.6 \pm 0.40$ & $12.2 \pm 2.62$ \\
\hline 75 & $8.2 \pm 0.91$ & $6.6 \pm 0.85$ & $6.6 \pm 1.04$ & $7.9 \pm 1.40$ & $6.6 \pm 0.66$ & $7.4 \pm 1.14$ \\
\hline \multicolumn{7}{|c|}{ Pencillium (\%) } \\
\hline 25 & $5.4 \pm 0.61$ & $6.9 \pm 0.44$ & $6.6 \pm 0.98$ & $7.4 \pm 1.35$ & $9.7 \pm 1.83$ & $6.6 \pm 0.99$ \\
\hline 50 & $5.2 \pm 0.68$ & $6.9 \pm 0.27$ & $6.3 \pm 0.57$ & $4.6 \pm 1.36$ & $8.9 \pm 1.17$ & $6.5 \pm 1.23$ \\
\hline 75 & $5.2 \pm 0.81$ & $6.3 \pm 0.37$ & $6.3 \pm 0.36$ & $3.3 \pm 1.19$ & $4.6 \pm 1.71$ & $6.5 \pm 1.45$ \\
\hline \multicolumn{7}{|l|}{ LSD: } \\
\hline treatment & & N.S. & & & 1.66 & \\
\hline fungi & & N.S. & & & 3.92 & \\
\hline concentration & & N.S. & & & 2.68 & \\
\hline
\end{tabular}

Values represent mean \pm standard error, ns: not significant at $P=0.05$. 
Table 3. Effects of fungal strains on seedling shoots and root dry biomass of millet varieties

\begin{tabular}{|c|c|c|c|c|c|c|}
\hline \multirow{2}{*}{ Millet variety } & \multicolumn{3}{|c|}{ Shoot dry weight (g) } & \multicolumn{3}{|c|}{ Root dry weight (g) } \\
\hline & Mallit & El-Fasher & MCSRC & Mallit & El-Fasher & MCSRC \\
\hline Control & $1.5 \pm 0.58$ & $8.35 \pm 0.95$ & $4.95 \pm 0.50$ & $0.2 \pm 0.06$ & $4.7 \pm 0.52$ & $3.35 \pm 0.49$ \\
\hline \multicolumn{7}{|c|}{ T. viride (\%) } \\
\hline 25 & $1.5 \pm 0.72$ & $3.7 \pm 0.46$ & $8.35 \pm 0.03$ & $0.6 \pm 0.35$ & $1.75 \pm 0.14$ & $2.4 \pm 0.83$ \\
\hline 50 & $2.4 \pm 0.06$ & $3.2 \pm 0.46$ & $6.45 \pm 0.55$ & $0.85 \pm 0.09$ & $1.65 \pm 0.32$ & $1.95 \pm 0.09$ \\
\hline 75 & $3.1 \pm 0.52$ & $2.6 \pm 0.12$ & $6.3 \pm 0.29$ & $1.7 \pm 0.17$ & $1.4 \pm 0.40$ & $1.65 \pm 0.32$ \\
\hline \multicolumn{7}{|c|}{ Pencillum (\%) } \\
\hline 25 & $2.9 \pm 0.17$ & $3.4 \pm 0.64$ & $4.95 \pm 0.03$ & $1.65 \pm 0.03$ & $1.65 \pm 0.20$ & $1.5 \pm 0.23$ \\
\hline 50 & $1.6 \pm 0.92$ & $3.3 \pm 0.27$ & $5.25 \pm 0.14$ & $1.0 \pm 0.58$ & $1.65 \pm 0.03$ & $1.45 \pm 0.20$ \\
\hline 75 & $1.25 \pm 0.32$ & $2.25 \pm 0.37$ & $5.3 \pm 0.12$ & $0.3 \pm 0.12$ & $0.75 \pm 0.03$ & $1.1 \pm 0.06$ \\
\hline LSD treatment & 1.65 & & & & 0.97 & \\
\hline LSD variety & 0.58 & & & & 0.34 & \\
\hline $\begin{array}{l}\text { LSD Conc. } \\
\text { LSD v.c }\end{array}$ & $\begin{array}{c}0.68 \\
0.48\end{array}$ & & & & $\begin{array}{l}0.39 \\
0.28\end{array}$ & \\
\hline
\end{tabular}

\subsection{Effect of Fungal Strains on Shoot and Root Length of Millet Seedlings}

By the end of experiment (day seven), seedlings of the millet verities selected for shoot and root measurements indicated significant growth differences with fungal application (Table 2). Trichoderma strain enhanced, compared to control, shoot growth of Mallit in all concentrations, improved shoot growth of El-Fasher up to concentration $(50 \%)$ and only in the lower concentration (25\%) with MCSRC. Whereas, Pencillium strain decreased the plumule growth of all varieties in all conc. compared to related controls. However, $75 \%$ of $T$. viride improved significantly plumule length of Mallit compared to other treatments. Both strains decrease significantly radicle length of all millet varieties. Reduction in seedling length of crop was also reported by Penicillium strains. Previously, it was found that Penicillium oxalicum caused marked reduction in shoot length of rice (17).

\subsection{Effect of Fungal Strains on Shoot and Root Dry Weights of Millet Seedlings}

The effect of fungus application on average dry matter weight of the germinated seedling of all the varieties were shown in (Table 3). The three millet varieties showed different response to fungus treatments in terms of dry biomass weight. Mallit variety showed improvement in dry biomasses (shoot + root weights) with fungus application, in contrast, El-Fasher variety showed reduction in the dry weight compared to their relative controls. On the other hand, MCSRC showed increase in the dry weight of shoot and decrease of root dry weight.

Trichoderma significantly increased seedling height, root length and root dry weight. Studies have confirmed the increase in root length and collar diameter, stem length and diameter of different plants by Trichoderma strains $(9 ; 10)$. A number of mechanisms for plant growth promotion by Trichoderma have been proposed. Trichoderma has been considered as a biofertilizer and a biocontrol, its effects on plants are through enhancing growth, production of antibiotics and parasitism of other fungi. In addition it is associated with increasing the availability of minerals and other ions, widespread rooting system which facilitates water and nutrient uptake and other plant growth regulators $(9 ; 16)$. Penicillium strains were reported to increase seedling growth of many crops and inhibit other fungal pathogens growth (17).

The stimulation of germination and early seedling growth of many plants are related to growth factors such as phytohormones including indole acetic acid, ethylene, zeatin and gibberellin. Moreover, most Trichoderma strains acidify their surrounding environment by secreting organic acids, such as gluconic, citric or fumaric acid $(9 ; 10)$. Fungi are highly efficient inducers of systemic and localized resistance in plants (3).

However, both strains were also reported to decrease germination and seedling development of some crop species $(8 ; 17 ; 18)$. Moreover, Penicillium and T. harzianum strains are commonly known to produce toxic substances, which threaten plants. Negative effects were mostly recorded when a large amount of inoculum of an antagonistic fungus were used on Striga germination. This was related to volatile metabolites which can act as anti-fungal or can inhibit development of some plant species and have phytotoxic effects (8).

\section{REFERENCES}


[1] Benítez T., Rincón, A.M., Limón, M. C. and Codón, A.C. (2004). Biocontrol mechanisms of Trichoderma strains. International Microbiology, 7: 249-260.

[2] Evidente, A. and Motta, A. (2001). Phytotoxins from fungi, pathogenic for agrarian, forestall and weedy plants. In: Tringali, C. (ed.). Bioactive Compounds from Natural Sources, Taylor \& Francis, London, UK, 473-525.

[3] Harman, G. E., Howell, C. R., Viterbo, A., Chet, I. and Lorito, M. (2004). Trichoderma species Opportunistic, a virulent plant symbionts. Nature Reviews Microbiology, 2: 43-56.

[4] Boari, A. and Vurro, M. (2004). Evaluation of Fusarium spp. and other fungi as biological control agents of broomrape (Orobanche ramosa). Biological Control, 30: 212-219.

[5] Aghavan,C H. (2005).Use of plant pathogens as bioherbicides to manage weeds in horticultural crops. Proceedings of the Florida State Horticultural Society, 118:208-214.

[6] Abouzeid, M. A. and El-Tarabily, K.A. (2010). Fusarium spp. suppress germination and parasitic establishment of bean and hemp broomrapes. Phytopathologia Mediterranea, 49: 51-64.

[7] Monte, E. (2001). Understanding Trichoderma: between biotechnology and microbial ecology. International Microbiology, 4: 1-4.

[8] Celar, F. and Valic, N. (2005). Effects of Trichoderma spp. and Gliocladium roseum culture filtrates on seed germination of vegetables and maize. Journal of Plant Diseases and Protection, 112 (4): 343-350.

[9] Okoth, S. A., Jane A. Otadoh and James O. Ochanda (2011). Improved seedling emergence and growth of maize and beans by Trichoderma harziunum. Tropical and Subtropical Agroecosystems, 13: 65 - 71
[10] Rahman, M. A., Sultana, R., Begum, M. F. and Alam, M. F. (2012). Effect of culture filtrates of Trichoderma on seed germination and seedling growth in chili. International Journal of Biosciences, 2 (4): 46-55.

[11] Johnston, A. and Booth, C. (1983). Plant Pathologist's Pocketbook. 2nd Ed. Commonwealth Mycological Institute, Kew, 439 p.

[12] Maguire, J.D. (1962). Speed of germination-aid in selection aid in evolution for seedling emergence and vigor. Crop Science, 2: 176-177.

[13] Randahawa, H.S.; Sharma, H.L.; Kaur, J. and Dalhiwal, A.S. (1985). Effects of fungicide on seed germination and seed mycofloras of wheat under different storage conditions. Pesticides, 2: 36-38.

[14] Mishra, D.S. and Sinha, A.P. (2000). Plant growth promoting activity of some fungal and bacteria agents on rice seed germination and seedling growth. Tropical Agric, 77: 188-191.

[15] Rabeendran, N, Moot, DJ, Jones, EE and Stewart, A. (2000). Inconsistent growth promotion of cabbage and lettuce from Trichoderma isolates. New Zealand Plant Protection, 53: 143-146.

[16] Raj, S. N., Shetty, N.P. and Shetty, H.S. (2005). Synergistic effects of Trichoshield on enhancement of growth and resistance to downy mildew in pearl millet. Biological Control, 50: 493-509.

[17] Islam, NF and Borthakur, SK (2012). Screening of mycota associated with Aijung rice seed and their effects on seed germination and seedling vigour. Plant Pathology and Quarantine, 2(1): 75-85. 